\title{
KOMPOSISI VEGETASI DAN CADANGAN KARBON PADA TINGKAT TIANG DAN POHON DI KAWASAN PARIWISATA ALAM BUKIT SULAP ZONA PEMANFAATAN TNKS KOTA LUBUKLINGGAU
}

\author{
Eti Susiana $^{1}$, Agus Susatya ${ }^{2}$, Hery Suhartoyo ${ }^{3}$ \\ 1) Mahasiswa Pasca Sarjana PSDAL, Perumnas Nikan Lubuklinggau \\ 2) Jurusan Kehutanan, Jl. W.R. Supratman Kandang Limun Kota Bengkulu \\ 3) Jurusan Kehutanan, Jl. W.R. Supratman Kandang Limun Kota Bengkulu \\ Email: umidzak@gmail.com
}

\begin{abstract}
ABSTRAK
Pemerintah kota Lubuklinggau mengembangkan pariwisata alam di zona pemanfaatan IPPA (Izin Pemanfaatan Pariwisata Alam) Bukit Sulap TNKS. Penelitian ini bertujuan untuk mengetahui nilai indeks penting jenis penyusun vegetasi dan besaran cadangan karbon pada tingkat tiang dan pohon di kawasan pariwisata alam Bukit Sulap zona pemanfaatan TNKS kota Lubuklinggau pada ketinggian 150 - $300 \mathrm{~m}$ dpl dan 300 $450 \mathrm{~m}$ dpl serta mengetahui besaran cadangan karbon yang akan hilang apabila area yang diizinkan untuk pembangunan sarana prasarana dibangun semuanya sebanyak 4,23 Ha. Penelitian ini dilakukan pada bulan Mei-Agustus 2017. Pengukuran biomasa pohon dilakukan dengan metode tanpa penebangan. Hasil penelitian di kawasan IPPA Bukit Sulap pada ketinggian 150 - $300 \mathrm{~m}$ dpl ditemukan 20 jenis spesies dengan spesies asli sebanyak 8 spesies, sedangkan pada kawasan dengan ketinggian 300-450 m dpl ditemukan 17 jenis spesies dengan spesies asli sebanyak 8 spesies. INP tertinggi tingkat pohon pada kawasan dengan ketinggian 150-300 m dpl didapat pada bendo (Artocarpus elasticus) sebesar 50,17\% sementara pada tingkat tiangnya terdapat pada glodokan tiang (Polyalthia longifolia) sebesar 47,97\%. INP tertinggi tingkat pohon pada kawasan dengan ketinggian 300-450 m dpl didapat pada waru (Hibiscus macrophyllus) sebesar $101,49 \%$ sementara pada tingkat tiangnya pada ki bugang (Arthrophyllum diversifolium) sebesar 78,77\%. Total cadangan karbon pada vegetasi tingkat pohon dan tiang di ketinggian 150-300 m dpl sebesar 105,824 Ton/Ha. Total cadangan karbon pada vegetasi tingkat pohon dan tiang di ketinggian 300-450 m dpl sebesar 70,037 Ton/Ha. Cadangan karbon total kedua kawasan penelitian adalah 87,930 Ton/Ha, sehingga dugaan cadangan karbon yang akan hilang adalah pada luasan area 4,23 $\mathrm{Ha}$ adalah 371,941 Ton karbon.
\end{abstract}

\section{Kata kunci : IPPA Bukit Sulap, Komposisi Vegetasi, Biomassa, Cadangan Karbon}

\section{PENDAHULUAN}

Taman Nasional Kerinci Seblat (TNKS) merupakan suatu kawasan yang memegang peranan yang amat penting bagi keseimbangan ekologi di Indonesia, khususnya di Sumatera, dimana TNKS ini mencakup beberapa propinsi di Sumatera, yaitu provinsi Jambi, Sumatera Barat, Sumatera Selatan dan Bengkulu. TNKS merupakan Taman Nasional terbesar di Sumatera dan nomor dua terbesar di Indonesia, yang memiliki kekhasan dalam kekayaan keanekaragaman flora dan fauna. TNKS berfungsi sebagai pengendali erosi, banjir dan merupakan sumber air dan dinyatakan sebagai paru-paru dunia (Kausar, 2010).

TNKS dikelola berdasarkan sistem zonasi yaitu pembagian kawasan ke dalam 
beberapa zona sesuai dengan karakteristik dan peruntukannya. Zonasi TNKS telah ditetapkan berdasarkan Surat Keputusan Direktur Jendral PHKA No.07/IVKK/2007 tanggal 16 Januari 2007 yang terdiri dari beberapa zona yaitu:

1. Zona Inti

2. Zona Rimba

3. Zona Pemanfaatan

4. Zona Rehabilitasi.

5. Zona Khusus

6. Zona Tradisional

Pengelolaan taman nasional telah diarahkan agar dapat berfungsi untuk melindungi sistem penyangga kehidupan, pengawetan keanekaragaman hayati beserta ekosistemnya, dan pemanfaatan secara lestari sumberdaya alam hayati beserta ekosistemnya karena keanekaragaman hayati merupakan modal bagi ekosistem awal dari taman nasional. Untuk mengelola keanekaragaman hayati ini diperlukan strategi yang dapat dikembangkan. Menurut Setiadi (2005) ada tiga aspek yang tercakup di dalamnya yaitu melindungi, mempelajari, dan memanfaatkan. Mempelajari struktur dan komposisi vegetasi yang terdapat di dalam taman nasional merupakan salah satu langkah untuk mendapatkan pengetahuan yang baik tentang ekologi dasar yang diperlukan dalam pengembangan suatu skema pengelolaan hutan secara lestari (Kartawinata, et., al. 2008).

Melalui keragaman vegetasi dapat pula ditentukan pendugaan serapan karbon dioksida $\left(\mathrm{CO}_{2}\right)$ oleh tegakan. Vegetasi hutan berperan dalam upaya peningkatan penyerapan $\mathrm{CO}_{2}$ dimana dengan bantuan cahaya matahari dan air dari tanah, vegetasi yang berklorofil mampu menyerap $\mathrm{CO}_{2}$ dari atmosfer melalui proses fotosintesis. Pendugaan serapan karbon dapat dihitung tanpa merusak tegakan dengan metode nondestruktif yang menggunakan persamaan allometrik yang telah diuji berdasarkan penelitian sebelumnya (Rusdiana, et. al., 2012 ).

Perubahan struktur vegetasi dalam suatu kawasan hutan sangat dipengaruhi oleh perubahan peruntukan lahannya. Struktur dan perkembangan vegetasi sangat dipengaruhi oleh faktor-faktor lingkungan serta dapat bereaksi terhadap perubahan lingkungan di sekitarnya (Susanti, R., et.,al., 2005). Perubahan peruntukan lahan menjadi kawasan wisata alam merupakan faktor lingkungan yang mempengaruhi perubahan struktur vegetasi dalam suatu kawasan hutan.

Pemerintah kota Lubuklinggau telah mengembangkan pariwisata alam di zona pemanfaatan IPPA (Izin Pemanfaatan Pariwisata Alam) Bukit Sulap TNKS. Bukit Sulap sendiri termasuk dalam wilayah seksi Pengelolaan Taman Nasional wilayah V Lubuklinggau, Bidang Pengelolaan Taman Nasional Wilayah III Bengkulu - Sumatera Selatan. Kawasan pariwisata alam Bukit Sulap ini terletak di ketinggian 450m dpl yang berarti kawasan Bukit Sulap ini termasuk hutan dataran rendah.

Pariwisata alam Bukit Sulap mulai beroperasi sejak tahun 2014. Luas areal total yang akan di usahakan sebagai ruang usaha seluas 42,375 Ha, adapun luas pengembangan sarana prasarana sesuai peraturan yang ada adalah maksimum $10 \%$ yaitu 4,23 Ha. Bukit Sulap berada di dekat pusat kota Lubuklinggau yang berjarak 2,1 $\mathrm{km}$ dengan jalan aspal hingga ke tepi kawasan hutan Bukit Sulap (Dokumen UKL-UPL Bukit Sulap, 2014).

Berdasarkan dokumen UKL-UPL pariwisata alam Bukit sulap maka pengembangan usaha sarana wisata alam dilakukan melalui kegiatan pembangunan, penyediaan dan pengusahaan fasilitas sarana wisata alam yang keberadaannya diperuntukkan sebagai penunjang kegiatan wisata alam, dan pengunjung memperoleh pelayanan dan kemudahan untuk menikmati produk dan jasa wisata alam. Usaha sarana wisata alam yang ada pada pariwisata Bukit Sulap ini meliputi : fasilitas pusat pengunjung, fasilitas ramburambu dan papan informasi, fasilitas pusat belanja, fasilitas parkir dan jalan kendaraan, fasilitas inklinator dan jalur 
setapak pegunungan, fasilitas tempat bersantai dan bermain, fasilitas edukasi, fasilitas akomodasi pengunjung, dan fasilitas emergency center/ security office.

Kawasan wisata alam Bukit Sulap ini menjadi salah satu destinasi wisata yang banyak pengunjungnya di Lubuklinggau, karena wilayahnya yang tidak jauh dari pusat kota dan sedikitnya destinasi wisata yang dimiliki oleh kota Lubuklinggau.

Adanya pembangunan usaha sarana wisata alam yang sesuai dengan peta peruntukannya pada zona pemanfaatan IPPA Bukit Sulap TNKS kota Lubuklinggau akan mempengaruhi keragaman vegetasi dan cadangan karbon tersimpan pada tingkat tiang dan pohon di kawasan tersebut. Sementara itu belum ada penelitian mengenai keragaman vegetasi dan pendugaan cadangan karbon tersimpan di bukit sulap khususnya kawasan IPPA. Oleh sebab itu perlu dilakukan penelitian mengenai komposisi vegetasi dan besaran cadangan karbon pada tingkat tiang dan pohon pada zona pemanfaatan IPPA Bukit Sulap TNKS kota Lubuklinggau yang dapat digunakan juga untuk menghitung pengaruh dari pemanfaatan pariwisata alam terhadap jumlah cadangan karbon di kawasan tersebut.

Penelitian ini bertujuan untuk mengetahui struktur dan komposisi hutan serta memperkirakan total besaran cadangan karbon di kawasan pariwisata alam Bukit Sulap zona pemanfaatan TNKS kota Lubuklinggau dan besaran karbon yang akan hilang apabila area yang diizinkan untuk pembangunan sarana prasarana dibangun semuanya sebanyak 4,23 Ha beserta usaha untuk meminimalisirnya.

\section{METODE PENELITIAN}

Penelitian ini dilaksanakan pada bulan Mei - Agustus 2017 di di kawasan IPPA Bukit Sulap zona pemanfaatan TNKS kota Lubuklinggau Sumatera Selatan.
Bahan-bahan yang digunakan dalam penelitian ini adalah, spesimen daun yang digunakan untuk identifikasi pohon, alkohol $70 \%$ yang digunakan sebagai pengawet spesimen dari lokasi penelitian. Alat-alat yang perlu disiapkan dalam penelitian ini antara lain : menyediakan peta lokasi, tali plastik, alat ukur tinggi pohon seperti haga meter, alat ukur diameter pohon seperti pita meter $100 \mathrm{~cm}$, meteran berukuran panjang 50 meter, parang, tally sheet dan alat tulis menulis dan GPS.

Pada penelitian ini data yang diambil dikhususkan pada stadium tiang dan pohon saja. Penelitian ini dibagi pada dua area ketinggian yakni pada ketinggian 150300 $\mathrm{m}$ dpl dan 300-450 m dpl. Penentuan areal lokasi penelitian dilakukan dengan metode purvosive sampling. Pengumpulan data komposisi dan struktur vegetasi dilakukan dengan analisis vegetasi, melalui tahapan sebagai berikut (Soerianegara dan Indrawan, 2002) :

1. Jalur pengamatan disesuaikan dengan jalur pendakian

2. Pembuatan titik-titik sampling menggunakan metode garis berpetak.

3. Pembagian vegetasi ke dalam tipe tiang dan pohon, setelah itu dilakukan pengambilan data vegetasi, yaitu:

- Tiang: pohon muda berdiameter 10 $\mathrm{cm}$ sampai kurang dari $20 \mathrm{~cm}$, diamati pada petak berukuran $10 \mathrm{x}$ $10 \mathrm{~m}$.

- Pohon: pohon dewasa berdiameter $20 \mathrm{~cm}$ atau lebih, diamati pada petak

berukuran 20 × $20 \mathrm{~m}$.

4. Parameter yang dicatat adalah jenis vegetasi, jumlah individu setiap jenis, diameter batang, tinggi pohon, dan koordinat pohon.

Ada 17 plot yang digunakan untuk pengamatan tingkat tiang dan pohon, pada kawasan IPPA Bukit Sulap. Pada ketinggian $150-300 \mathrm{~m}$ dpl ada 8 plot dan pada ketinggian $300-450 \mathrm{~m}$ dpl ada 9 plot. 


\section{Analisis Data}

Komposisi Vegetasi

Untuk analisis identifikasi jenis vegetasi dilakukan secara deskriptif sedangkan untuk data vegetasi lainnya dilakukan analisis secara kuantitatif (Soerianegara dan Indrawan, 2002), yaitu dengan menghitung nilai Kerapatan Suatu Jenis (K), Kerapatan Relatif (KR), Frekuensi Jenis $(\mathrm{F})$, Dominansi suatu Jenis (D), Dominansi Relatif (DR), hingga diperoleh Indeks Nilai Penting (INP). Selanjutnya menghitung Indeks Keragaman Jenis Shanon- Wienner (Odum, 1971) dan Indeks Kesamaan Jenis Sorenson (1948) dalam Odum (1996).

Nilai Kerapatan Suatu Jenis (K) dianalisis dengan persamaan:

$\mathrm{K}=\frac{\text { Jumlah individu }}{\text { Jumlah seluruh plot }}$

Nilai Kerapatan Relatif (KR) dianalisis dengan persamaan:

$\mathrm{KR}=\frac{\text { Kerapatan dari suatu jenis }}{\text { Kerapatan dari seluruh jenis }} \mathrm{x} 100 \%$

Nilai Frekuensi Suatu Jenis (F) dianalisis dengan persamaan:

$\mathrm{F}=\frac{\text { Jumlah plot ditemukan suatu jenis }}{\text { Jumlah seluruh plot }}$

Nilai Frekuensi Relatif (FR) dianalisis dengan persamaan:

$$
\mathrm{FR}=\frac{\text { Frekuensi dari suatu jenis }}{\text { Frekuensi seluruh jenis }} \times 100 \%
$$

Nilai Dominansi suatu Jenis (D) dianalisis dengan persamaan:

Dominasi (D) $=\frac{\text { Jumlah bidang dasar }}{\text { Luas contoh }}$

Nilai Dominansi Relatif (DR) dianalisis dengan persamaan:

Dominasi Relatif $(D R)=\frac{\text { Dominasi dari suatu jenis }}{\text { Dominasi dari seluruh jenis }} \times 100 \%$

Total Biomassa $=\mathrm{BK}_{1}+\mathrm{BK}_{2}+\ldots \ldots . . \mathrm{BK}_{\mathrm{n}}$

Maka dari seluruh persamaan di atas, dapat diperoleh Indeks Nilai Penting, yaitu sebagai berikut:

$\mathrm{INP}=\mathrm{FR}+\mathrm{KR}+\mathrm{DR}$ (Untuk tingkat tiang dan pohon)

Indeks Keragaman Jenis dianalisis menggunakan persamaan ini:
$\mathrm{H}^{\mathrm{I}}=-\sum \frac{\mathrm{ni}}{\mathrm{N}} \log \frac{n i}{N}$

Dengan:

$\mathrm{ni}=$ Jumlah individu dari suatu jenis $\mathrm{i}$

$\mathrm{N}=$ Jumlah total individu seluruh jenis

Indeks Kesamaan Jenis dianalisis menggunakan persamaan Sorensen:

$\mathrm{IS}=2 \mathrm{C} /(\mathrm{A}+\mathrm{B})$

Dimana :

IS = Indeks kemiripan komunitas

A = Jumlah jenis pada ketinggian 150 $300 \mathrm{~m} \mathrm{dpl}$

$\mathrm{B}=$ Jumlah jenis pada ketinggian $300-$ $450 \mathrm{~m} \mathrm{dpl}$

$\mathrm{C}=$ Jumlah jenis yang sama pada ketinggian 150 - $300 \mathrm{~m}$ dpl dan pada ketinggian $300-450 \mathrm{~m}$ dpl.

\section{Besaran Cadangan Karbon}

Metode yang digunakan dalam penelitian ini yaitu metode non-destructive dengan menggunakan metode allometrik. Metode non-destructive adalah metode perhitungan biomassa tanpa melakukan perusakan pada tegakan-tegakan yang ada dengan menggunakan rumus allometrik yang ada. Rumus allometrik yang digunakan dalam penelitian ini adalah rumus Allometrik Ketterings (Hairiah dan Rahayu, 2007).

$$
\begin{aligned}
& \text { BK = 0,11 } \mathbf{~} \boldsymbol{\rho} \times \mathbf{D}^{\mathbf{2 . 6 2}} \\
& \text { Keterangan : } \\
& \text { BK } \quad=\text { Berat Kering }(\mathrm{Kg}) \\
& \rho \quad=\text { Berat Jenis Kayu }\left(\mathrm{g} \mathrm{cm}^{-3}\right) \\
& \mathrm{D} \quad=\text { Diameter Pohon }(\mathrm{cm})
\end{aligned}
$$

Biomassa per satuan luas $=\frac{\text { Total biomasssa }}{\text { Luas area }\left(\mathrm{m}^{2}\right)}$

Cadangan karbon $=$ Biomassa per satuan luas x 0,46 (Ton/Ha) 


\section{Hasil dan Pembahasan}

\section{Komposisi Vegetasi}

Hasil penelitian di kawasan IPPA Bukit Sulap pada ketinggian 150-300 m dpl menunjukkan terdapat 20 spesies tingkat tiang dan pohon dari 8 plot yang ada. Pada kawasan ini terdapat 8 spesies asli yang berasal dari kawasan tersebut atau sebanyak $40 \%$ sementara sisanya dari luar kawasan . Spesies asli tersebut adalah bendo (Artocarpus elasticus), awar-awar (Ficus septica), meranti (Shorea Spp), ara (Ficus ribes), embacang (Mangifera foetida), ki bugang (Arthropyllum diversifolium), beringin (Ficus Benjamina), rukam (Flacourtia rukam).

Jumlah spesies tingkat tiang dan pohon yang ditemukan pada kawasan ketinggian 300-450 m dpl sebanyak 17 spesies dari 9 plot yang ada. Pada kawasan ini terdapat 8 spesies asli berasal dari kawasan tersebut atau sebanyak $47,06 \%$ sementara sisanya berasal dari luar kawasan. Spesies asli tersebut adalah meranti (Shorea Spp), ara (Ficus ribes), bendo (Artocarpus elasticus), pohon lilin (permentiera cereifera), ki bugang (Arthropyllum diversifolium), jengkol (Pithecalobium lobatum), pohon salam (Syzygium polyanthum). rukam (Flacourtia rukam). Semua spesies yang terdapat pada kedua kawasan disajikan pada tabel 4.1 dan tabel 4.2.

Tabel 1. Daftar Vegetasi Tingkat Tiang dan Pohon Pada Ketinggian 150 - 300 m dpl.

\begin{tabular}{ll}
\hline \multicolumn{1}{c}{ Nama Jenis } & \multicolumn{1}{c}{ Nama Latin } \\
\hline Waru & Hibiscus macrophyllus \\
Kemiri & Aleurites moluccana \\
Sawo duren & Manilkara zapota \\
Meranti & Shorea Spp \\
Ara & Ficus ribes \\
Bendo & Artocarpus elasticus \\
Belimbing & Averrhoa carambola \\
Pohon lilin & Permentiera cereifera \\
Ki Bugang & Arthrophyllum diversifolium \\
Kenanga hutan & Cananga odorata \\
Durian & Durio zibethinus \\
Flamboyan & Delonix regia \\
Jengkol & Pithecalobium lobatum \\
Kapuk & Ceiba pentandra \\
Pohon salam & Syzygium polyanthum \\
Sengon & Paraserianthes falcataria \\
Rukam & Flacourtia rukam \\
\hline
\end{tabular}

Tabel 2. Daftar Vegetasi Tingkat Tiang dan Pohon Pada Ketinggian 300 - 450 m dpl.

\begin{tabular}{ll}
\hline Nama Jenis & Nama Latin \\
\hline Waru & Hibiscus macrophyllus \\
Kemiri & Aleurites moluccana \\
Sawo duren & Manilkara zapota \\
Meranti & Shorea Spp \\
Ara & Ficus ribes \\
Bendo & Artocarpus elasticus \\
Belimbing & Averrhoa carambola \\
Pohon lilin & Permentiera cereifera \\
Ki Bugang & Arthrophyllum diversifolium \\
Kenanga hutan & Cananga odorata \\
Durian & Durio zibethinus \\
Flamboyan & Delonix regia \\
Jengkol & Pithecalobium lobatum \\
Kapuk & Ceiba pentandra \\
Pohon salam & Syzygium polyanthum \\
Sengon & Paraserianthes falcataria \\
Rukam & Flacourtia rukam \\
\hline
\end{tabular}

INP tingkat Pohon pada ketinggian 150$300 \mathrm{~m}$ dpl

Besarnya Indeks nilai penting menunjukkan peran jenis yang bersangkutan dalam komunitasnya atau pada lokasi penelitian.

Tabel 3. menunjukkan pada tingkat pohon di ketinggian 150-300 m dpl, didapat Indeks nilai penting tertinggi dimiliki oleh Artocarpus elasticus diikuti Durio zibethinus, Aleurites Moluccana, Ficus septica dan Manilkara zapota.

Jenis bendo, durian, kemiri, ara, dan sawo duren merupakan jenis pohon yang mendominasi di ketinggian 150-300 m dpl kawasan IPPA Bukit Sulap karena memiliki nilai INP tertinggi. Kemampuan kelimanya dalam menempati sebagian besar lokasi penelitian menunjukkan bahwa kelimanya memiliki kemampuan beradaptasi dengan kondisi lingkungan pada seluruh wilayah penelitian (Arrijani, et.,al.2006).

Tabel 4. menunjukkan Indeks nilai penting tertinggi pada tingkat tiang di ketinggian 150-300 m dpl terdapat pada Polyalthia longifolia, diikuti Hibiscus macrophyllus, Ficus ribes, Pinus merkusii dan Swietenia macrophylla.

Dengan membandingkan 5 (lima) nilai INP tertinggi antara tingkat pertumbuhan pohon dan tiang di kawasan 
IPPA pada ketinggian 150-300 m dpl, maka terlihat komposisi jenis yang cukup berbeda. Menurut Dendang B (2015), jika jenis dominan pada tingkat pohon telah mencapai puncak pertumbuhan, maka jenis pada tingkat tiang akan naik menjadi tingkat pohon. Maka pada masa yang akan datang pada area ini akan sedikit berbeda jenis vegetasi yang akan mendominasi pada tingkat pohonnya

Tabel 5. menunjukkanIndeks nilai penting tertinggi pada tingkat pohon di ketinggian 300-450 m dpl terdapat pada Hibiscus macrophyllus, diikuti oleh Aleurites moluccana, Manilkara zapota,
Shorea Spp dan Ficus ribes. Berdasarkan nilai INP setiap spesies masing - masing kawasan penelitian terdapat perbedaan spesies yang memiliki INP tertinggi pada tingkat pertumbuhan pohon ini. Pada kawasan dengan ketinggian 150-300 m dpl nilai INP tertingginya terdapat pada bendo (Artocarpus elasticus), sementara pada kawasan dengan ketinggian 300-450 m dpl nilai INP tertingginya terdapat pada waru (Hibiscus macrophyllus). moluccana) dan sawo duren (Manilkara Zapota).

Tabel 6. menunjukkan Indeks nilai penting tertinggi pada tiang di ketinggian

Tabel 3 Indeks Nilai Penting Tingkat Pohon Pada Ketinggian 150-300 m dpl

\begin{tabular}{llcccc}
\hline \multicolumn{1}{c}{ Nama Jenis } & \multicolumn{1}{c}{ Nama Latin } & KR & FR & DR & INP \\
\hline Bendo & Artocarpus elasticus & $\mathbf{1 1 , 5 3 8}$ & $\mathbf{9 , 6 7 7}$ & $\mathbf{2 8 , 9 5 6}$ & $\mathbf{5 0 , 1 7 1}$ \\
Durian & Durio zibethinus & $\mathbf{1 3 , 4 6 2}$ & $\mathbf{9 , 6 7 7}$ & $\mathbf{1 5 , 1 7 8}$ & $\mathbf{3 8 , 3 1 7}$ \\
Kemiri & Aleurites moluccana & $\mathbf{9 , 6 1 5}$ & $\mathbf{6 , 4 5 2}$ & $\mathbf{1 7 , 4 0 0}$ & $\mathbf{3 3 , 4 6 7}$ \\
Awar-awar & Ficus septica & $\mathbf{9 , 6 1 5}$ & $\mathbf{1 2 , 9 0 3}$ & $\mathbf{5 , 0 7 8}$ & $\mathbf{2 7 , 5 9 6}$ \\
Sawo duren & Manilkara zapota & $\mathbf{9 , 6 1 5}$ & $\mathbf{6 , 4 5 2}$ & $\mathbf{6 , 8 3 3}$ & $\mathbf{2 2 , 9 0 0}$ \\
Waru & Hibiscus macrophyllus & 9,615 & 6,452 & 5,411 & 21,478 \\
Kenanga hutan & Cananga odorata & 5,769 & 9,677 & 5,722 & 21,169 \\
Meranti & Shorea Spp & 5,769 & 6,452 & 6,856 & 19,076 \\
Ara & Ficus ribes & 3,846 & 9,677 & 1,744 & 15,268 \\
Flamboyan & Delonix regia & 7,692 & 3,226 & 2,322 & 13,240 \\
Belimbing & Averrhoa carambola & 3,846 & 6,452 & 0,956 & 11,253 \\
Karet & Havea brasiliensis & 3,846 & 3,226 & 1,467 & 8,539 \\
Embacang & Mangifera foetida & 1,923 & 3,226 & 1,067 & 6,216 \\
Nangka & Artocarpus heterophyllus & 1,923 & 3,226 & 0,656 & 5,804 \\
Pinus & Pinus merkusii & 1,923 & 3,226 & 0,356 & 5,504 \\
\hline \multicolumn{1}{c}{ Total } & 100,000 & 100,000 & 100,000 & 300,000 \\
\hline
\end{tabular}

Sumber : data primer olah 2017

Tabel 4. Indeks Nilai Penting Tingkat Tiang Pada Ketinggian 150-300 m dpl

\begin{tabular}{|c|c|c|c|c|c|}
\hline Nama Jenis & Nama Latin & KR & FR & DR & INP \\
\hline Glodokan tiang & Polyalthia longifolia & 22,951 & 8,000 & 17,019 & 47,970 \\
\hline Waru & Hibiscus macrophyllus & 11,475 & 12,000 & 15,433 & 38,909 \\
\hline Ara & Ficus ribes & 9,836 & 16,000 & 8,562 & 34,398 \\
\hline Pinus & Pinus merkusii & $\mathbf{9 , 8 3 6}$ & 4,000 & 12,051 & 25,887 \\
\hline Mahoni & Swietenia macrophylla & 11,475 & 4,000 & 9,197 & 24,672 \\
\hline Belimbing & Averrhoa carambola & 6,557 & 12,000 & 5,603 & 24,160 \\
\hline Sawo Duren & Manilkara zapota & 6,557 & 8,000 & 6,660 & 21,217 \\
\hline Flamboyan & Delonix regia & 4,918 & 8,000 & 6,765 & 19,683 \\
\hline Meranti & Shorea $S p$ & 4,918 & 8,000 & 5,074 & 17,992 \\
\hline Awar-awar & Ficus septica & 3,279 & 8,000 & 4,545 & 15,824 \\
\hline Ki bugang & Arthrophyllum diversifolium & 3,279 & 4,000 & 3,383 & 10,661 \\
\hline Beringin & Ficus benjamina & 3,279 & 4,000 & 3,171 & 10,450 \\
\hline Rukam & Flacourtia rukam & 1,639 & 4,000 & 2,537 & 8,176 \\
\hline Total & & 100,000 & 100,000 & 100,000 & 300,000 \\
\hline
\end{tabular}

Sumber : Data primer olah 2017 
Tabel 5. Indeks Nilai Penting Tingkat Pohon Pada Ketinggian 300 - 450 m dpl

\begin{tabular}{llcccc}
\hline \multicolumn{1}{c}{ Nama Jenis } & \multicolumn{1}{c}{ Nama Latin } & KR & FR & DR & INP \\
\hline Waru & Hibiscus macrophyllus & $\mathbf{4 8 , 0 0 0}$ & $\mathbf{2 2 , 2 2 2}$ & $\mathbf{3 1 , 2 6 8}$ & $\mathbf{1 0 1 , 4 9 1}$ \\
Kemiri & Aleurites moluccana & $\mathbf{1 0 , 0 0 0}$ & $\mathbf{7 , 4 0 7}$ & $\mathbf{1 8 , 8 1 7}$ & $\mathbf{3 6 , 2 2 5}$ \\
Sawo duren & Manilkara zapota & $\mathbf{1 0 , 0 0 0}$ & $\mathbf{1 1 , 1 1 1}$ & $\mathbf{1 3 , 1 2 1}$ & $\mathbf{3 4 , 2 3 2}$ \\
Meranti & Shorea Spp & $\mathbf{6 , 0 0 0}$ & $\mathbf{1 1 , 1 1 1}$ & $\mathbf{3 , 4 5 5}$ & $\mathbf{2 0 , 5 6 6}$ \\
Ara & Ficus ribes & $\mathbf{6 , 0 0 0}$ & $\mathbf{7 , 4 0 7}$ & $\mathbf{3 , 7 6 7}$ & $\mathbf{1 7 , 1 7 4}$ \\
Bendo & Artocarpus elasticus & 4,000 & 7,407 & 4,451 & 15,859 \\
Belimbing & Averrhoa carambola & 2,000 & 3,704 & 7,160 & 12,863 \\
Pohon lilin & Permentiera cereifera & 2,000 & 3,704 & 7,019 & 12,723 \\
Ki Bugang & Arthrophyllum diversifolium & 4,000 & 7,407 & 1,136 & 12,544 \\
Kenanga hutan & Cananga odorata & 2,000 & 7,407 & 1,790 & 11,197 \\
Durian & Durio zibethinus & 2,000 & 3,704 & 4,156 & 9,859 \\
Flamboyan & Delonix regia & 2,000 & 3,704 & 3,253 & 8,957 \\
Jengkol & Pithecalobium lobatum & 2,000 & 3,704 & 0,607 & 6,311 \\
\hline Total & & 100,000 & 100,000 & 100,000 & 300,000 \\
\hline
\end{tabular}

Sumber : Data primer olah 2017

300-450 m dpl terdapat pada jenis Arthrophyllum diversifolium (78,77\%), diikuti oleh Shorea Spp (55,56\%), Hibiscus macrophyllus $(50,49 \%)$, Ficus ribes $(43,56 \%)$ dan Delonix regia $(18,64 \%)$. Hal ini menunjukkan bahwa Arthrophyllum diversifolium merupakan jenis tanaman yang bisa beradaptasi dengan baik walaupun di bawah kanopi pohon hutan lainnya. Hasil penelitian Kusumo A (2016) menyebutkan bahwa jenis vegetasi yang ditemukan pada setiap tingkat pohon, tiang, pancang dan semai menunjukkan bahwa jenis ini mampu berkembang baik dibawah naungan pohon.

\section{Indeks Keragaman Jenis Shanon - Wienner (H')}

Berdasarkan INP seluruh jenis pada masing-masing ketinggian area, maka dihitung indeks keragaman jenisnya. Hasil perhitungan menunjukkan bahwa indeks keragaman jenis tingkat pohon pada ketinggian 150 - $300 \mathrm{~m}$ dpl sebesar 1,108 dan indeks keragaman jenis tingkat tiang pada ketinggian 150 - $300 \mathrm{~m}$ dpl sebesar 1,020 .

Sedangkan indeks keragaman jenis tingkat pohon pada ketinggian $300-450 \mathrm{~m}$ dpl sebesar 0,691 dan indeks keragaman jenis tingkat tiang pada ketinggian 300 - 450 m dpl sebesar 0,795.

Berdasarkan kriteria Barbour et.,al. (1987) maka indeks keragaman jenis tingkat pohon dan tiang pada ketinggian 150-300 m dpl termasuk dalam kriteria sedang, sementara indeks keragaman jenis tingkat pohon dan tiang pada ketinggian 300-450 m dpl termas uk dalam kriteria rendah. Indeks keragaman jenis sedang artinya keanekaragaman jenis dalam setiap tingkat pertumbuhan tergolong stabil $\left(1<\mathrm{H}^{\prime}<2\right)$. Indeks keragaman rendah artinya keanekaragaman jenis dalam setiap tingkat pertumbuhan tergolong kurang stabil.

Tabel 6. Indeks Nilai Penting Tingkat Tiang Pada Ketinggian $300-450 \mathrm{~m}$ dpl

\begin{tabular}{llcccc}
\multicolumn{1}{c}{ Nama Jenis } & \multicolumn{1}{c}{ Nama Latin } & KR & FR & DR & INP \\
\hline Ki bugang & Arthrophyllum diversifolium & $\mathbf{3 5 , 2 1 1}$ & $\mathbf{1 0 , 3 4 5}$ & $\mathbf{3 3 , 2 2 0}$ & $\mathbf{7 8 , 7 7 6}$ \\
Meranti & Shorea Sp & $\mathbf{1 8 , 3 1 0}$ & $\mathbf{2 0 , 6 9 0}$ & $\mathbf{1 6 , 5 6 8}$ & $\mathbf{5 5 , 5 6 7}$ \\
Waru & Hibiscus macrophyllus & $\mathbf{1 6 , 9 0 1}$ & $\mathbf{1 3 , 7 9 3}$ & $\mathbf{1 9 , 7 9 6}$ & $\mathbf{5 0 , 4 9 1}$ \\
Ara & Ficus ribes & $\mathbf{1 4 , 0 8 5}$ & $\mathbf{1 7 , 2 4 1}$ & $\mathbf{1 2 , 2 3 4}$ & $\mathbf{4 3 , 5 6 0}$ \\
Flamboyan & Delonix regia & $\mathbf{4 , 2 2 5}$ & $\mathbf{1 0 , 3 4 5}$ & $\mathbf{4 , 0 7 8}$ & $\mathbf{1 8 , 6 4 8}$ \\
Bendo & Artocarpus elasticus & 2,817 & 6,897 & 4,758 & 14,471 \\
Kapuk & Ceiba pentandra & 2,817 & 6,897 & 2,889 & 12,602 \\
Pohon salam & Syzygium polyanthum & 1,408 & 3,448 & 2,379 & 7,236 \\
Durian & Durio zibethinus & 1,408 & 3,448 & 1,444 & 6,301 \\
Sengon & Paraserianthes falcataria & 1,408 & 3,448 & 1,359 & 6,216 \\
Rukam & Flacourtia rukam & 1,408 & 3,448 & 1,274 & 6,131 \\
\hline Total & & 100,00 & 100,00 & 100,00 & 300,00 \\
\hline Sumber & & & &
\end{tabular}

Sumber : data primer olah 2017 


\section{Indeks Kesamaan Komunitas (IS)}

Nilai indeks similaritas atau kesamaan komunitas (IS) digunakan untuk mengetahui kesamaan antar tiap komunitas atau kawasan yang diteliti. Semakin besar nilai indeks kesamaan komunitas (IS), maka kesamaan jenis kedua komunitas yang dibandingkan semakin seragam komposisi jenisnya.

Berdasarkan kriteria Barbour et.,al. (1987), maka nilai indeks kesamaan komunitas tingkat pohon pada ketinggian 150-300 m dpl dan 300-450 m dpl termasuk dalam kriteria tinggi, artinya kesamaan jenis kedua komunitas yang dibandingkan semakin seragam komposisinya. Sementara itu, nilai indeks kesamaan komunitas tingkat tiang pada ketinggian 150-300 m dpl dan 300-450 m dpl termasuk dalam kriteria rendah, artinya kesamaan jenis kedua komunitas yang dibandingkan tidak terlalu seragam komposisinya.

\section{Pendugaan Cadangan Karbon}

Tabel 7. Menunjukkan Menunjukkan bahwa cadangan karbon tersimpan terbesar pada tingkat tiang dan pohon di ketinggian 150-300 $\mathrm{m}$ dpl dalah pada bendo (Artocarpus elasticus) sebesar 31,83 Ton/Ha, diikuti oleh Durio zibethinus, Aleurites moluccana, dan Manilkara zapota . Total karbon tersimpan pada vegetasi tingkat tiang dan pohon di ketinggian 150-300 m dpl adalah sebesar 105,824 Ton/Ha.

Tabel 7. Cadangan Karbon Tingkat Tiang dan Pohon Pada Ketinggian 150-300 m dpl

\begin{tabular}{lcc}
\hline \multicolumn{1}{c}{ Nama Latin } & $\begin{array}{c}\text { Biomassa } \\
\text { (Ton/Ha) }\end{array}$ & $\begin{array}{c}\text { Karbon } \\
\text { Tersimpan }\end{array}$ \\
\hline Ficus ribes & 3,497 & 1,609 \\
Ficus septica & 10,834 & 4,984 \\
Averrhoa carambola & 2,242 & 1,031 \\
Artocarpus elasticus & 69,206 & 31,835 \\
Durio zibethinus & 45,245 & 20,813 \\
Mangifera foetida & 3,125 & 1,438 \\
Delonix regia & 6,704 & 3,084 \\
Havea brasiliensis & 2,841 & 1,307 \\
Aleurites moluccana & 28,376 & 13,053 \\
Cananga odorata & 8,822 & 4,058 \\
Shorea Spp & 3,898 & 1,793 \\
Artocarpus heterophyllus & 1,506 & 0,693 \\
Pinus merkusii & 2,002 & 0,921 \\
Manilkara zapota & 23,117 & 10,634 \\
Hibiscus macrophyllus & 14,277 & 6,568
\end{tabular}

\begin{tabular}{lcc} 
Arthrophyllum diversifolium & 0,371 & 0,171 \\
Ficus benjamina & 0,365 & 0,168 \\
Polyalthia longifolia & 2,086 & 0,960 \\
Swietenia macrophylla & 1,159 & 0,533 \\
Flacourtia rukam & 0,380 & 0,175 \\
\hline
\end{tabular}

Sumber : Data Primer olah 2017

Bendo memiliki cadangan karbon terbesar dibandingkan jenis vegetasi yang lain karena diameter pohon bendo yang cukup besar dibanding pohon lainnya dan jumlahnya banyak dibanding jenis vegetasi lainnya walaupun berat jenisnya kecil. Begitu pula dengan durian (Durio zibethinus) dan kemiri (Aleurites moluccana) yang memiliki cadangan karbon cukup besar karena diameter pohonnya yang besar meskipun berat jenisnya kecil.

Tabel 8. Cadangan Karbon Tingkat Tiang dan Pohon Pada Ketinggian 300-450 m dpl

\begin{tabular}{lcc}
\hline \multicolumn{1}{c}{ Nama Latin } & $\begin{array}{c}\text { Biomassa } \\
\text { (Ton/Ha) }\end{array}$ & $\begin{array}{c}\text { Karbon } \\
\text { Tersimpan }\end{array}$ \\
\hline Ficus ribes & 6,308 & 2,902 \\
Arthrophyllum diversifolium & 4,766 & 2,192 \\
Averrhoa carambola & 0,749 & 0,344 \\
Artocarpus elasticus & 4,820 & 2,217 \\
Durio zibethinus & 8,481 & 3,901 \\
Delonix regia & 2,778 & 1,278 \\
Pithecalobium lobatum & 0,760 & 0,349 \\
Aleurites moluccana & 19,697 & 9,061 \\
Cananga odorata & 1,151 & 0,529 \\
Shorea Spp & 6,935 & 3,190 \\
Permentiera cereifera & 14,900 & 6,854 \\
Manilkara zapota & 26,350 & 12,121 \\
Hibiscus macrophyllus & 53,519 & 24,619 \\
Ceiba pentandra & 0,331 & 0,152 \\
Syzygium polyanthum & 0,426 & 0,196 \\
Flacourtia rukam & 0,177 & 0,081 \\
Paraserianthes falcataria & 0,108 & 0,050 \\
& 152,255 & 70,037 \\
\hline Sumber Data primer olah 2017 & &
\end{tabular}

Tabel 8. Menunjukkan cadangan karbon terbesar pada tingkat pohon pada ketinggian 300-450 m dpl adalah pada waru (Hibiscus macrophyllus) sebesar 24,61 Ton/Ha, diikuti oleh sawo duren (Manilkara zapota) sebesar 12,12 Ton/Ha, dan kemiri (Aleurites moluccana) sebesar 9,06 Ton/Ha. Total cadangan karbon pada tingkat pertumbuhan tiang dan pohon pada ketinggian 300-450 m dpl sebesar 70,037 ton/Ha. waru (Hibiscus macrophyllus) memiliki cadangan karbon lebih besar dibandingkan jenis vegetasi yang lain pada ketinggian 300-450 m dpl karena memiliki diameter pohon yang cukup besar dan 
kerapatan vegetasi yang cukup besar pula dibanding spesies lainnya.

Total cadangan karbon pada kawasan 300-450 m dpl lebih kecil dibandingkan dengan cadangan karbon pada kawasan 150$300 \mathrm{~m}$ dpl. Hal ini dimungkinkan karena diameter dan kerapatan pohon pada ketinggian 150-300 m dpl lebih besar dibandingkan pada pohon di ketinggian 300$450 \mathrm{~m}$ dpl.

Dibandingkan dengan penelitian serupa di kawasan hutan primer dataran rendah siberut Sumatera barat yang memiliki cadangan karbon sebesar 60,68 Ton/Ha (Bismark et al., 2008), maka cadangan karbon tingkat pohon pada kedua kawasan penelitian ini memiliki cadangan karbon yang yang lebih tinggi yakni sebesar 105,824 Ton/Ha dan 70,037 Ton/Ha pada masing-masing kawasan penelitian. Namun dibandingkan penelitian serupa lainnya di hutan tropis dataran rendah Ulu Gadut Sumatera Barat oleh Suwardi A.B dkk, dimana cadangan karbon pada kawasan tersebut sebesar 241,38 Ton/Ha maka cadangan karbon pada kawasan pariwisata bukit sulap ini jauh lebih rendah.

\section{Pendugaan Cadangan Karbon Yang Hilang}

Pembangunan sarana dan prasarana pada kawasan pariwisata alam Bukit Sulap kota Lubuklinggau sesuai dengan dokumen UKL-UPLnya hanya diperbolehkan $10 \%$ dari total seluruh kawasan yakni hanya 4,23 Ha saja yang dibangun menjadi sarana dan prasarana kawasan pariwisata alam. Sehingga didapat pendugaan cadangan karbon yang akan hilang dan harus segera diantisipasi dalam pengelolaannnya nanti. Cadangan karbon total kedua kawasan penelitian adalah 87,930 Ton/Ha, sehingga dugaan cadangan karbon yang akan hilang adalah pada luasan area 4,23 $\mathrm{Ha}$ adalah 371,941 Ton karbon.

\section{KESIMPULAN}

Pada kawasan dengan ketinggian 150-300 m dpl ditemukan 20 jenis spesies dengan spesies asli kawasan tersebut sebanyak 8 spesies. Sedangkan kawasan dengan ketinggian 300-450 m dpl ditemukan 17 jenis spesies dengan spesies asli kawasan tersebut sebanyak 8 spesies. INP tertinggi tingkat pohon pada kawasan dengan ketinggian 150-300 m dpl terdapat pada bendo (Artocarpus elasticus) sebesar $50,17 \%$ sementara pada tingkat tiangnya terdapat paada glodokan tiang (Polyalthia longifolia) sebesar 47,97\%. Sementara itu INP tertinggi tingkat pohon pada kawasan dengan ketinggian 300-450 m dpl terdapat pada waru (Hibiscus macrophyllus) sebesar $101,49 \%$ sementara pada tingkat tiangnya terdapat paada ki bugang (Arthrophyllum diversifolium) sebesar 78,77\%.

Total cadangan karbon pada vegetasi tingkat pohon dan tiang di ketinggian 150$300 \mathrm{~m} \mathrm{dpl}$ adalah sebesar 105,824 Ton/Ha. Sementara itu total cadangan karbon pada vegetasi tingkat pohon dan tiang di ketinggian 300-450 m dpl adalah sebesar 70,037 Ton/Ha. Cadangan karbon total kedua kawasan penelitian adalah 87,930 Ton/Ha, sehingga dugaan cadangan karbon yang akan hilang adalah pada luasan area 4,23 Ha adalah 371,941 Ton karbon.

\section{DAFTAR PUSTAKA}

Arrijani, Setiadi, D.,Guhardja, E., Qayim, I. 2006. analisis vegetasi hulu DAS cianjur taman nasional gunung gede pangrango. Biodiversitas 7 (2) : 147-153.

Barbour, M.G., J.H. Burk, and W.D. Pitts.1987. Terrestrial Plant Ecology. San Fransisco : The Benjamin / Cummings Publishing Company, Inc.

Dendang B., dan Handayani W.2015. Struktur dan komposisi tegakan hutan di taman Nasional Gunung Gede Pangrango, Jawa Barat. PROS SEM NAS MASY BIODIV INDON.1(4) : 691-695.

Hairiah K, Rahayu S. 2007. Petunjuk Praktis Pengukuran Karbon Tersimpan di Berbagai Macam Penggunaan Lahan. Bogor : World Agroforestry 
Centre-ICRAF, SEA Regional Office, University of Brawijaya, Unibraw, Indonesia.

Ismaini, L., Lailati,M., rustandi.,Sunandar, D.2015. Analisis komposisi dan keanekaragaman tumbuhan di Gunung Dempo Sumatera Selatan. PROS SEM NAS MASY BIODIV INDON. 1 (6) : 1397-1402

Kartawinata K, Purwaningsih, Partomihardjo T. 2008. Floristic and Structure of a Lowland Dipterocarp Forest at Wanariset Samboja, East Kalimantan, Indonesia. Reinwardtia 12 (4) : 301-323.

Kausar. 2010. konflik kepentingan dibalik konservasi studi di taman nasional kerinci seblat (TNKS) Provinsi Jambi. Indonesian Journal Of Agricultural Economics (IJAE). 2(1) :133-149.

Keputusan Menteri Kehutanan Republik Indonesia No. 70/Kpts-II/2001. Jakarta.

Kusumo, A., Bambang, A.N., dan Izzati, M. 2016. Struktur vegetasi kawasan hutan alam dan hutan terdegradasi di Taman Nasional Tesso Nilo. Jurnal Ilmu Lingkungan Undip. 14 (1) : 19-26.

Odum, E.P. 1971. Fundamentals of Ecology. Third Edition. Philadelphia: W.B.

PT. Linggau Bisa. 2014. Rencana Pengembangan Pariwisata Alam
Pada Zona Pemanfaatan Bukit Sulap Taman Nasional Kerinci Seblat (TNKS) Di Kota Lubuklinggau. Dokumen UKLUPL.

Rusdiana, O dan Lubis R.,S. 2012. Pendugaan korelasi antara karakteristik tanah terhadap cadangan karbon (Carbon Stock) pada hutan sekunder. Silvikultur Tropika 3 (01) : 14-21.

Setiadi, D. 2005. Keanekaragaman spesies tingkat pohon di taman wisata alam Ruteng, Nusa Tenggara Timur. Biodiversitas 6 (2) : 118-122

Soerianegara, I dan A. Indrawan. 2002. Ekologi Hutan Indonesia. Departemen Manajemen Hutan. Fakultas Kehutanan IPB. Bogor. Sounders Co.

Susanti, R., Dayat, E. 2005. Analisis vegetasi kawasan mata air panas gemurak desa penindaian kecamatan semendo darat laut Kabupaten Muara Enim Sumatera Selatan. Forum MIPA. 9 (1) : 2536.

Suwardi,A., B., Mukhtar, E., dan Syamsuardi. 2013. Komposisi jenis dan cadangan karbon di hutan tropis dataran rendah , Ulu Gadut, Sumatera Barat. Berita Biologi 12(2) : $\quad$ 169-176. 